\title{
Oxygen Uptake Recovery Kinetics after the 6-Minute Walk Test in Patients with Chronic Obstructive Pulmonary Disease
}

\author{
Florent Baty $^{a} \quad$ Arnoldus J.R. van Gestel ${ }^{a, b} \quad$ Lukas Kern $^{a} \quad$ Martin H. Brutsche ${ }^{a}$

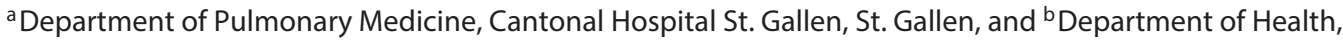 \\ Zurich University of Applied Sciences, Winterthur, Switzerland
}

\begin{abstract}
Key Words
Oxygen uptake kinetics · 6-Minute walk test - Mobile cardiopulmonary monitoring $\cdot$ Submaximal exercise . Cardiopulmonary exercise testing
\end{abstract}

\begin{abstract}
Background: There is a growing interest in exercise parameters capable of objectively evaluating the functional capacity of patients with chronic obstructive pulmonary disease (COPD). Objectives: The purpose of the present study was to analyze breath-by-breath cardiopulmonary and gas exchange recovery responses of patients with COPD after a 6-minute walk test (6MWT). Methods: Oxygen uptake $\left(\mathrm{VO}_{2}\right)$ kinetics of patients were obtained using mobile telemetric cardiopulmonary monitoring during and after a 6MWT. Recovery kinetics were modelled using a 4-parameter nonlinear logistic model. Multiple linear regression was performed to assess the association between the half-time of recovery of oxygen consumption $\left(\mathrm{T}_{1 / 2}, \mathrm{VO}_{2}\right)$ and exercise capacity (6-minute walking distance, 6MWD). Results: Sixty-nine patients with COPD (28 females) with a mean age of $65 \pm 10$ years took part in the study. After adjustment for covariates (body mass index, forced expiratory volume in $1 \mathrm{~s}$, forced vital capacity, and age), $\mathrm{T}_{1 / 2} \mathrm{VO}_{2}$ was significantly associated with 6MWD $(p=0.002)$. Conclusions: $\mathrm{T}_{1 / 2} \mathrm{VO}_{2}$ can be used to
\end{abstract}

reflect exercise capacity in patients with COPD. As $\mathrm{T}_{1 / 2} \mathrm{VO}_{2}$ mostly depends on the rate of increase in pulmonary blood flow, the results of the present study underline the importance of cardiocirculatory impairment for exercise intolerance in patients with COPD.

(c) 2016 S. Karger AG, Basel

\section{Introduction}

There is a growing interest in exercise parameters capable of objectively evaluating the functional capacity of patients with chronic obstructive pulmonary disease (COPD) [1]. The maximum rate of oxygen consumption $\left(\mathrm{VO}_{2 \max }\right)$ is a key physiological determinant of exercise capacity and is routinely measured during rapid ramped incremental exercise to the limit of tolerance [2]. Quantification of $\mathrm{VO}_{2 \max }$ using symptom-limited exercise testing has been challenged because it requires a maximal effort of patients who are rarely used to strenuous activity and may be influenced by conditions other than the underlying disease [3]. In addition, since most activities

A.J.R. van Gestel deceased on June 3, 2016.

F. Baty and A.J.R. van Gestel contributed equally to this article.

\section{KARGER}

E-Mail karger@karger.com

www.karger.com/res
(C) 2016 S. Karger AG, Basel

0025-7931/16/0926-0371\$39.50/0
Martin $\mathrm{H}$. Brutsche, $\mathrm{MD}, \mathrm{PhD}$

Department of Pulmonary Medicine

Cantonal Hospital St. Gallen

CH-9007 St. Gallen (Switzerland)

E-Mail martin.brutsche@ kssg.ch 
of daily living are performed in a nonincremental fashion and at submaximal level of exertion, the 6-minute walk test (6MWT) is representative of daily-life activities and may, therefore, accurately reflect the functional capacity of patients $[2,4]$.

The 6MWT is often used in clinical practice and research studies because of its inexpensiveness, reproducibility, responsiveness to standardization, and embodiment of an essential functional task, but the 6-minute walking distance (6MWD) may lack sensitivity to detect subtle information about functional capacity [2]. $\mathrm{VO}_{2} \mathrm{ki}$ netics during the initial phase of low-intensity exercise $\left(\mathrm{VO}_{2}\right.$ on-kinetics) provide important information about oxygen delivery and muscle metabolism and have proven to be very successful in reflecting functional capacity in patients with COPD and in patients with other diseases [5-10]. Accordingly, $\mathrm{VO}_{2}$ on-kinetics in patients with COPD are independently associated with the 6MWD and $\mathrm{VO}_{2}$ during steady state $\left(\mathrm{VO}_{2 \mathrm{SS}}\right)$ as presented in previous work [11]. As the limited cardiopulmonary reserve in these patients appears to affect exercise responses, it may be postulated that it also affects the recovery phase. Recovery kinetics of oxygen uptake $\left(\mathrm{VO}_{2}\right.$ off-transient kinetics) reflect the ability to recover from exercise that is indicative of daily life. In healthy subjects, $\mathrm{VO}_{2}$ declines immediately and rapidly $[12,13]$, and $\mathrm{VO}_{2}$ off-transient kinetics have been used as an index of oxidative capacity $[14,15]$. An even faster adjustment recovery from submaximal exercise has been demonstrated in trained athletes [16]. Although numerous researchers have used $\mathrm{VO}_{2}$ off-transient kinetics to successfully quantify exercise capacity in patients with heart failure $[3,17,18]$, no such data exist in patients with COPD. Given the vast pathophysiological heterogeneity of this disease, it may be reasonable to presume that different stages of COPD differ in terms of $\mathrm{VO}_{2}$ recovery kinetics. Therefore, the main objective of the present study was to analyze $\mathrm{VO}_{2}$ recovery kinetics in patients with COPD by using mobile telemetric cardiopulmonary monitoring (MOB). More specifically, we investigated the extent to which $\mathrm{VO}_{2}$ recovery kinetics are associated with established parameters of exercise capacity $\left(\mathrm{VO}_{2 \mathrm{SS}}\right.$ and $\left.6 \mathrm{MWD}\right)$.

\section{Materials and Methods}

\section{Study Design}

We performed a cross-sectional observational study in patients with COPD (GOLD classification II-IV). Patients referred to the Pulmonary Division of the Basel University Hospital, Switzerland, between August 2003 and June 2007 were considered for participa-

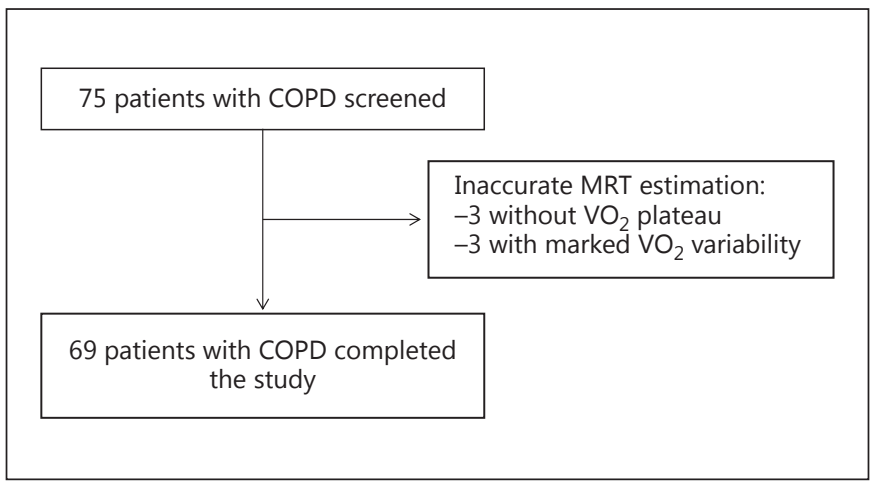

Fig. 1. Study synopsis. COPD, chronic obstructive pulmonary disease; MRT, mean response time.

tion in the study (Fig. 1). Exclusion criteria were as follows: need for oxygen supply or resting transcutaneous oxygen saturation $\left(\mathrm{SpO}_{2}\right)$ of $<85 \%$ while breathing room air, inability to walk, any acute coronary event during the previous month, and conditions precluding the use of a face mask (e.g., anatomic anomaly, claustrophobia, or panic disorder). Part of the study population data have also been used in other studies evaluating the feasibility, safety, and clinical usefulness of a MOB-enhanced 6MWT $[19,20]$.

\section{6-Minute Walk Test}

All patients performed the 6MWT following pulmonary function testing. The $6 \mathrm{MWD}$ was measured according to the guidelines of the American Thoracic Society (ATS) [21] with a standardized encouragement [22] in a 30-m corridor. An experienced technician supervised it. Before starting the $6 \mathrm{MWT}$, patients rested seated for 3-5 min until stable $\mathrm{VO}_{2}$ values were recorded $\left(\mathrm{VO}_{2 \text { rest }}\right)$. The $6 \mathrm{MWT}$ was followed by a recovery phase of $5 \mathrm{~min}$, where the patient rested on a chair.

\section{$6 M W T$ with a MOB Device}

Indirect calorimetry was performed using the Oxycon Mobile ${ }^{\circledR}$ (Viasys Healthcare, Yorba Linda, CA, USA) portable, wireless cardiopulmonary exercise testing device in order to quantify breathby-breath oxygen exchange kinetics during the $6 \mathrm{MWT}$. Pulse rate was determined using an electrocardiogram-triggered belt (Polar ${ }^{\circledR}$ Electro OY T-61). $\mathrm{SpO}_{2}$ was measured using a finger clip. $\mathrm{VO}_{2}$ and carbon dioxide output, tidal volumes, and breathing frequency were assessed using a face mask (dead space $<70 \mathrm{ml}$ ) with a flow sensor and a gas analyzer. The patient carried data storage and transfer units by wearing a dedicated harness. Wireless transfer of breathby-breath data to a laptop computer allowed real-time monitoring. Feasibility and safety of MOB has been tested in previous work by performing both the $6 \mathrm{MWT}$ and $\mathrm{MOB}$ on consecutive days in random order [19]. The additional weight ( $950 \mathrm{~g}$ ) of the equipment had no effect on the walking distance [19]. The exact 6MWT-MOB procedure has been previously described [8]. Exercise capacity was quantified by $6 \mathrm{MWD}$ and $\mathrm{VO}_{2 \mathrm{ss}}$. Criteria for maximal effort were defined according to ATS guidelines. A ventilatory limitation was reached when the patient had a ventilatory reserve $<11 \mathrm{~L}$ or $<15 \%$ of the maximal voluntary ventilation. A cardiac limitation was defined when a patient reached a maximal heart rate $\geq 90 \%$ of predicted. 


\section{Pulmonary Function}

Spirometry, whole body plethysmography, and diffusion capacity measurements were performed according to the ATS and the European Respiratory Society guidelines [12, 13]. Postbronchodilator spirometry was performed on the same day as the exercise tests (6MWT).

\section{Mean Response Time Reparametrization}

Following the onset of constant workload exercise, $\mathrm{O}_{2}$ uptake increase (i.e., on-kinetics) can be characterized by the time (mean response time, MRT) required for $\mathrm{VO}_{2}$ to achieve $63 \%$ of the $\mathrm{VO}_{2 \mathrm{SS}}$ in response to physical stress. A new MRT index (MRT corrected for work rate, wMRT) was calculated to quantify $\mathrm{VO}_{2}$ kinetics by correcting MRT for work rate during the first phase of the 6MWT. This reparametrization has been described in previously published work [20]. The difference between $\mathrm{O}_{2}$ uptake at rest and during effort $\left(\mathrm{VO}_{2 \mathrm{SS}}-\mathrm{VO}_{2 \text { rest }}\right)$ was used as a proxy for work rate during the first phase of the 6MWT. MRT was then reparametrized as follows:

$$
w M R T=\frac{M R T}{V O_{2 S S}-V O_{2 r e s t}} .
$$

\section{Oxygen Uptake Recovery}

The kinetics of $\mathrm{VO}_{2}$ during recovery were characterized by the recovery half-time $\left(\mathrm{T}_{1 / 2} \mathrm{VO}_{2}\right)$ which is defined as the time needed for $\mathrm{VO}_{2}$ to decrease from its peak value (at the end of the 6MWT) by half (in seconds).

\section{Statistical Data Analysis}

Continuous variables were expressed as means and standard deviations, 95\% confidence intervals, and percentages for frequencies. Between-group differences of continuous variables were tested using linear models (ANOVA F test). Univariate linear regression was performed to assess the association between variables reflecting cardiopulmonary and gas exchange function and also exercise capacity $\left(\mathrm{VO}_{2 \mathrm{SS}}\right.$ and 6MWD). Variables significantly associated with $6 \mathrm{MWD}$ and $\mathrm{VO}_{2 \mathrm{SS}}$ in the univariate analysis were included in a multivariate analysis. Mixed-effects nonlinear regression was used to fit the oxygen uptake curves. A $p$ value of $<0.05$ was considered to indicate statistical significance. All the analyses were done using the R statistical software [23], including the packages drc for curve fitting $[24,25]$ as well as medrc [26] and nlme [27], for nonlinear mixed effects modelling, and multcomp for parameter inference [28].

\section{Curve Fitting of Oxygen Uptake}

Original breath-by-breath data were imported from the MOB device. Raw data were preprocessed by averaging the breath-bybreath measurements over consecutive periods of $20 \mathrm{~s}$. The time interval chosen for averaging is in agreement with the recommendations from the ATS statement on cardiopulmonary exercise testing [2] and based on empirical evaluation of the signal-to-noise ratio of the breath-by-breath data obtained from the MOB device. Oxygen uptake recovery curves were modelled using the following nonlinear 4-parameter logistic equation, which is characterized by a mono-exponential decay:

$$
V O_{2}=V O_{2 \text { rec }}+\frac{\left(V O_{2 S S}-V O_{2 r e c}\right)}{\left(1+e^{\tau\left(\text { time }-T_{1 / 2} V O_{2}\right)}\right)},
$$

Table 1. Anthropometrics, pulmonary function, and 6-minute walking distance

$\begin{array}{lc}\text { Anthropometrics } & \\ \text { Subjects, } n & 69 \\ \text { Female/male, } n & 28 / 41 \\ \text { Age, years } & 66(60-73) \\ \text { Body mass index } & 23.8(20.1-28.1) \\ \text { Pulmonary function } & \\ \mathrm{FEV}_{1}, \mathrm{~L} & 1.0(0.8-1.3) \\ \mathrm{FEV}_{1}, \% \text { predicted } & 39.1(34.3-56.2) \\ \mathrm{FEV}_{1} / \mathrm{FVC} \text { ratio } & 0.45(0.34-0.54) \\ \text { 6-Minute walking distance, } \mathrm{m} & 345(265-392)\end{array}$

Values are presented as medians (interquartile ranges). $\mathrm{FEV}_{1}$, forced expiratory volume in $1 \mathrm{~s} ; \mathrm{FEV}_{1} / \mathrm{FVC}$ ratio, forced expiratory volume in $1 \mathrm{~s}$ expressed as percent of forced expiratory vital capacity. with $\tau$, the steepness of the curve; $\mathrm{VO}_{2 \mathrm{rec}}$, the $\mathrm{VO}_{2}$ at recovery; $\mathrm{VO}_{2 S \mathrm{SS}}$, the $\mathrm{VO}_{2}$ at steady state; and $\mathrm{T}_{1 / 2} \mathrm{VO}_{2}$, the position of the inflection point corresponding to the half-time recovery. This model was fitted jointly to the set of oxygen recovery kinetics using mixed-effects nonlinear regression as implemented in the $\mathrm{R}$ package medrc [29]. Parameters estimates for each COPD GOLD stage and associated hypothesis testing were carried out within the mixed-model framework.

\section{Statement of Ethics}

All patients gave informed consent. The local institutional review board approved the study.

\section{Results}

\section{Patients' Characteristics}

Sixty-nine patients with moderate-to-severe COPD, a median age of 66 years (interquartile range 60-73), and a forced expiratory volume in $1 \mathrm{~s}\left(\mathrm{FEV}_{1}\right)$ of $39 \%$ (interquartile range 34-56) predicted were included in our study. In 4 patients, curve fitting was unsatisfactory, leading to their exclusion from the analysis. Two distinct patterns of response to exercise were noticed in this group: in 3 patients, oxygen uptake did not show a plateau, and in 2 patients, $\mathrm{VO}_{2}$ showed a marked variability after reaching a plateau. Variable walking speed and pauses during the $6 \mathrm{MWT}$ are the most likely explanations for this observation. The exclusion process is depicted in Figure 1. Anthropometrical characteristics, lung function, respiratory symptoms, and exercise capacity data of the patients with COPD are presented in Table 1. 
Fig. 2. Oxygen uptake kinetics of all patients according to their GOLD stage (red line, GOLD stage II; green line, GOLD stage III; and blue line, GOLD stage IV). The 3 different phases of the overall kinetics (rest, exercise, and recovery kinetics) are separated by vertical dotted lines. The superimposed black line represents the illustrative fit of a global empirical model on the overall data set. (Colors refer to the online version only.)

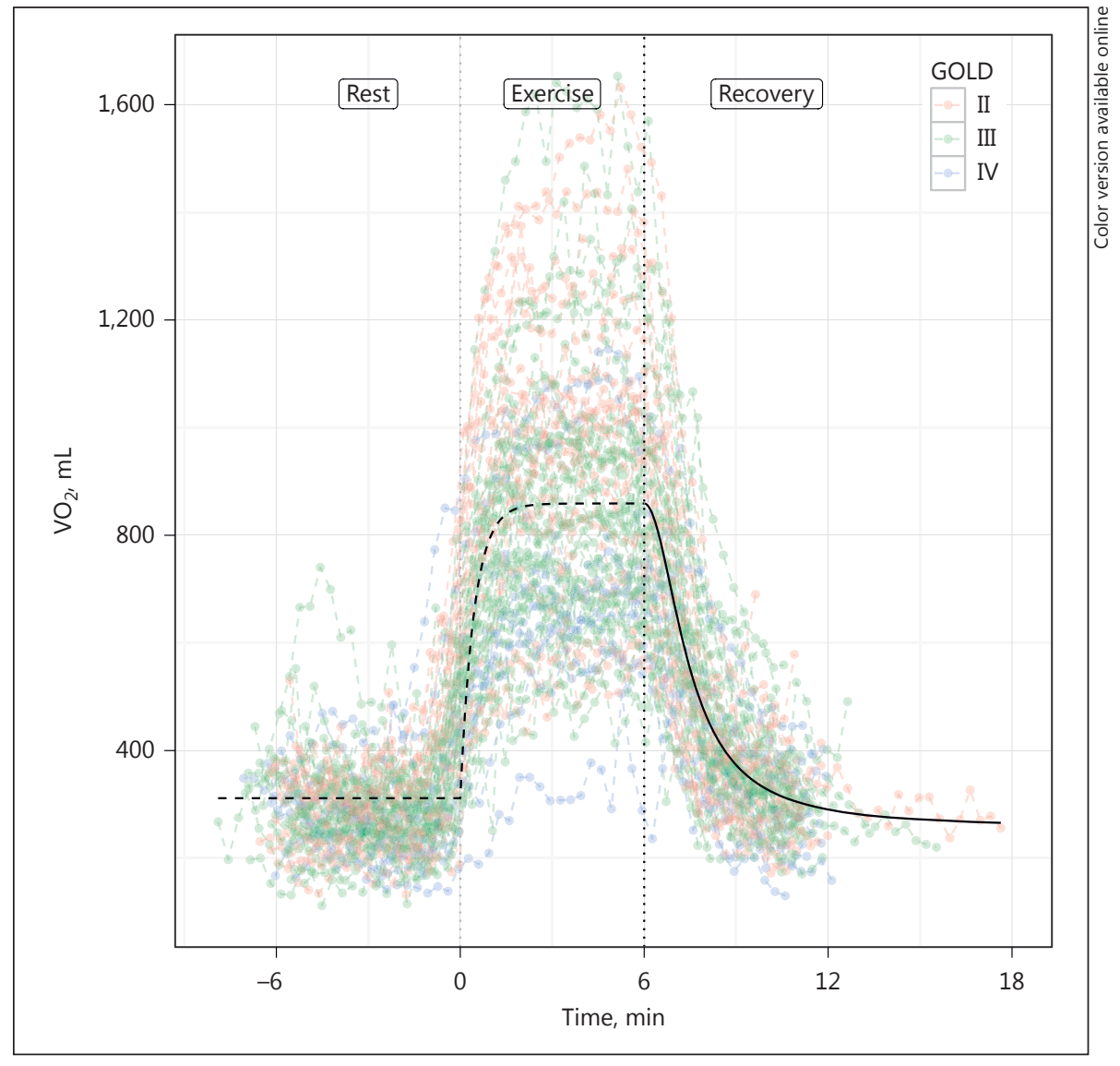

Table 2. Characteristics of patients

\begin{tabular}{|c|c|c|c|}
\hline & GOLD II & GOLD III & GOLD IV \\
\hline Subjects, $n$ & 21 & 37 & 11 \\
\hline Females, $n$ & 10 & 13 & 5 \\
\hline Body mass index & $28.3(26.3-30.2)$ & $23.6(22.2-25.1)$ & $20.5(17.8-23.2)$ \\
\hline $\mathrm{FEV}_{1}, \mathrm{~L} / \mathrm{s}$ & $1.5(1.4-1.7)$ & $1.0(0.9-1.1)$ & $0.7(0.6-0.9)$ \\
\hline FVC, L & $2.8(2.4-3.1)$ & $2.6(2.3-2.9)$ & $2.1(1.6-2.5)$ \\
\hline $\mathrm{VO}_{2 \mathrm{rec}}, \mathrm{mL}$ & $313.8(265.5-356.6)$ & $286.0(269.2-302.8)$ & $217.4(174.0-260.7)$ \\
\hline $\mathrm{VO}_{2 \mathrm{SS}}, \mathrm{mL}$ & $1,004.1(902.0-1,106.3)$ & $847.8(770.9-924.8)$ & $697.1(556.0-838.3)$ \\
\hline $\mathrm{T}_{1 / 2} \mathrm{VO}_{2}, \mathrm{~s}$ & $1,11.3(81.8-140.8)$ & $143.2(120.1-166.4)$ & $160.3(112.4-208.2)$ \\
\hline Walking distance, $\mathrm{m}$ & $359.1(315.7-402.6)$ & $331.8(299.1-364.5)$ & $298.6(238.6-358.5)$ \\
\hline Dyspnea, Borg scale & $4.1(3.1-5.1)$ & $5.4(4.7-6.1)$ & $4.8(3.5-6.1)$ \\
\hline MRT, $\min$ & $1.2(1.0-1.3)$ & $1.2(1.0-1.3)$ & $1.4(1.1-1.7)$ \\
\hline
\end{tabular}

The patients are grouped into 3 categories according to GOLD stages. Data are presented as mean estimates (95\% confidence intervals). $\mathrm{FEV}_{1}$, forced expiratory volume in $1 \mathrm{~s} ; \mathrm{FVC}$, forced expiratory vital capacity; $\mathrm{FEV}_{1} / \mathrm{FVC}$ ratio, forced expiratory volume in $1 \mathrm{~s}$ expressed as percent of forced expiratory vital capacity; $\tau$, the steepness of the curve during recovery; $\mathrm{VO}_{2 \mathrm{rec}}$, the lower asymptote; $\mathrm{VO}_{2 \mathrm{SS}}$, the upper asymptote at recovery; $\mathrm{T}_{1 / 2} \mathrm{VO}_{2}$, half-time recovery of oxygen uptake; MRT, mean response time; wMRT, mean response time corrected for work rate. 
Fig. 3. $\mathrm{VO}_{2}$ uptake recovery kinetics curves of all patients according to their GOLD stage (red line, GOLD stage II; green line, GOLD stage III; and blue line, GOLD stage IV). This representation superimposes the oxygen recovery kinetics with the fitted curves provided by fixed-effects estimates of the joint mixed model. (Colors refer to the online version only.)

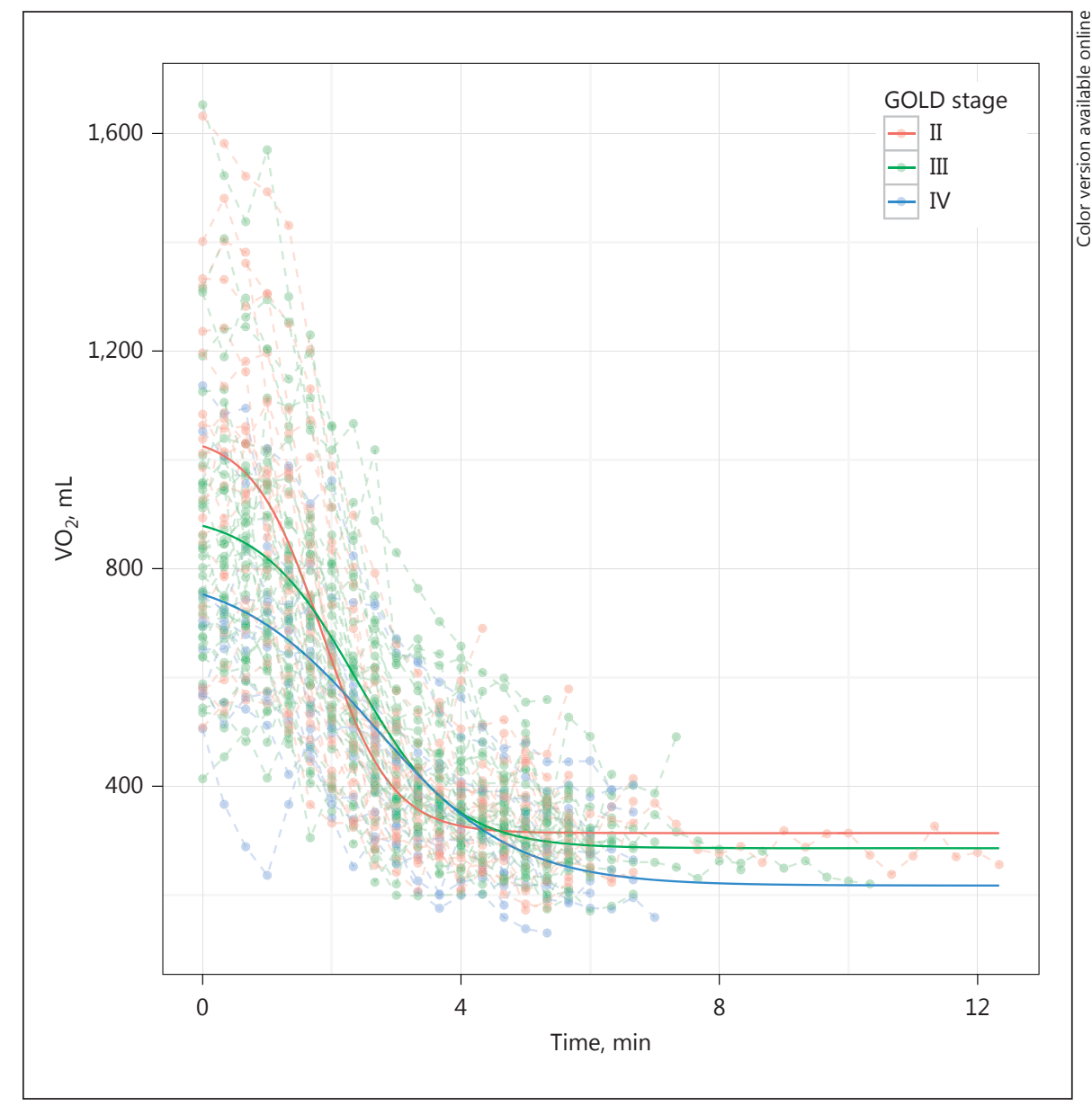

\section{Exercise Capacity and Oxygen Kinetics}

Patients' characteristics including oxygen kinetics parameter estimates are provided for each GOLD stage in Table 2 . The ventilatory and cardiac limitations are also reported. Overall, 59\% of patients reached criteria for maximal effort. A high proportion of patients with advanced GOLD stages reached ventilatory limitations. Cardiac limitations were relatively higher in lower GOLD stages. Figure 2 shows the overall $\mathrm{VO}_{2}$ uptake kinetics of all patients according to their GOLD stage. The resting period of $5 \mathrm{~min}$ is followed by a period of rapid growth at the onset of exercise, settling into a steady-state level $\left(\mathrm{VO}_{2 \mathrm{SS}}\right)$ after approximately $3 \mathrm{~min}$. Figure 3 shows the oxygen uptake recovery kinetics of the patients together with the fitted sigmoidal curves in the different GOLD stages. The steepness of the curves $(\tau)$ significantly differed between stages II and IV $(p<0.001)$ and between stages III and IV $(p=0.047)$. The half-time recovery $\left(\mathrm{T}_{1 / 2}\right.$ $\mathrm{VO}_{2}$ ) significantly differed between stages II and III ( $p=$ $0.004)$.

Oxygen Kinetics during Recovery of the 6-Minute Walk Test

\section{Determinants of Exercise Capacity}

Determinants of exercise capacity as defined by the 2 dependent variables $\mathrm{VO}_{2 s s}$ and $6 \mathrm{MWD}$ were investigated. $\mathrm{VO}_{2 s \mathrm{~s}}$ was a significant predictor of $6 \mathrm{MWD}$ (linear regression estimate $0.20,95 \%$ CI $0.12-0.28, p<0.001)$. The results of the univariate linear regression analysis summarizing the association between a series of predictors and both $\mathrm{VO}_{2 S S}$ and 6MWD are listed in Table 3. There was a significant association between exercise capacity (6MWD) and both wMRT and $\mathrm{T}_{1 / 2} \mathrm{VO}_{2}(p<0.001)$. The association between $6 \mathrm{MWD}$ and $\mathrm{T}_{1 / 2} \mathrm{VO}_{2}$ remained significant after adjusting for the confounding covariate indicating whether patients reached their ventilatory or cardiac limitation $(p<0.001)$. In addition, $\mathrm{VO}_{2 S S}$ showed significant associations with body mass index, $\mathrm{FEV}_{1}$, forced vital capacity, maximum heart rate, heart rate reserve, wMRT, and $\mathrm{VO}_{2}$ at rest. After adjustment for covariates (body mass index, $\mathrm{FEV}_{1}$, age, and forced vital capacity) in multiple linear regression analysis (Table 4 ), $\mathrm{T}_{1 / 2} \mathrm{VO}_{2}$ was significantly associated with 6MWD $(p=0.002)$. 
Table 3. Determinants of exercise capacity

\begin{tabular}{|c|c|c|c|c|c|c|}
\hline & \multicolumn{3}{|l|}{ 6MWD } & \multicolumn{3}{|l|}{$\mathrm{VO}_{2 S S}$} \\
\hline & estimate & std. error & $p$ & estimate & std. error & $p$ \\
\hline Body mass index & 1.66 & 2.36 & 0.484 & 27.09 & 4.99 & $<0.001$ \\
\hline $\mathrm{FEV}_{1}, \mathrm{~L} / \mathrm{s}$ & 50.75 & 29.56 & 0.091 & 270.55 & 68.74 & $<0.001$ \\
\hline $\mathrm{FEV}_{1}, \%$ predicted & 1.52 & 0.83 & 0.071 & 6.96 & 1.96 & $<0.001$ \\
\hline $\mathrm{HR}_{\text {reserve }}, \mathrm{bpm}$ & -0.54 & 0.57 & 0.342 & -3.81 & 1.37 & 0.007 \\
\hline $\mathrm{HR}_{\text {rest }}, \mathrm{bpm}$ & -1.31 & 0.86 & 0.132 & -2.50 & 2.18 & 0.257 \\
\hline $\mathrm{wMRT}, \mathrm{min}^{2} / \mathrm{mL}$ & $-23,953.4$ & $8,080.4$ & 0.004 & $-117,278.42$ & $16,146.4$ & $<0.001$ \\
\hline $\mathrm{VE}_{\text {rest }}, \mathrm{L} / \mathrm{min}$ & -1.16 & 2.88 & 0.688 & 13.28 & 7.10 & 0.066 \\
\hline $\mathrm{VO}_{2 \text { rest }}, \mathrm{mL}$ & 0.06 & 0.12 & 0.641 & 0.86 & 0.28 & 0.003 \\
\hline
\end{tabular}

The association between the dependent variables 6-minute walking distance and oxygen level at steady state and a set of explanatory variables were tested using univariate linear regression analysis. $6 \mathrm{MWD}$, 6-minute walking distance; $\mathrm{VO}_{2 \mathrm{SS}}$, oxygen uptake at steady sate; std. error, standard error; $\mathrm{FEV}_{1}$, forced expiratory volume in $1 \mathrm{~s}$; FVC, forced expiratory vital capacity; HR, mean heart rate; VE, mean ventilation; wMRT, mean response time corrected for work rate; $\mathrm{VO}_{2 \text { rest }}$, oxygen uptake at rest; $\mathrm{T}_{1 / 2} \mathrm{VO}_{2}$, half-time recovery of oxygen uptake.

Table 4. Predictors of exercise capacity

\begin{tabular}{lrrrr}
\hline & Estimate & Std. error & $t$ value & $p$ value \\
\hline $6 M W D$ & & & & \\
Intercept & 348.58 & 93.15 & 3.74 & $<0.001$ \\
$\mathrm{~T}_{1 / 2} \mathrm{VO}_{2}, \mathrm{~s}$ & -0.48 & 0.15 & -3.28 & 0.002 \\
Body mass index $_{\text {FEV }}, \mathrm{L}$ & 0.24 & 2.39 & 0.10 & 0.919 \\
Age, years & 3.69 & 36.39 & 0.10 & 0.920 \\
FVC, L & 0.11 & 1.24 & 0.09 & 0.933 \\
\hline VO2SS & 14.71 & 16.52 & 0.89 & 0.377 \\
Intercept & & & & \\
$\mathrm{T}_{1 / 2}$ VO & \\
Body, $\mathrm{s}$ & -19.91 & 200.53 & -0.10 & 0.921 \\
FEV, L & -0.30 & 0.31 & -0.95 & 0.345 \\
Age, years & 22.33 & 5.14 & 4.35 & $<0.001$ \\
FVC, L & 129.27 & 78.33 & 1.65 & 0.104 \\
\hline
\end{tabular}

The association between the dependent variables 6-minute walking distance (6MWD) and oxygen uptake at steady state $\left(\mathrm{VO}_{2 \mathrm{SS}}\right)$ and a set of explanatory variables was tested using multiple linear regression analysis. Std. error, standard error; $\mathrm{T}_{1 / 2} \mathrm{VO}_{2}$, halftime recovery of oxygen uptake; $\mathrm{FEV}_{1}$, forced expiratory volume in $1 \mathrm{~s}$; FVC, forced expiratory vital capacity.

\section{Discussion}

The analysis of oxygen kinetics during the 6MWT provides important information on exercise capacity in patients with COPD. On-kinetics parameters including wMRT showed a significant association with 6MWD and $\mathrm{VO}_{2 s s}$. wMRT increased according to the level of disease severity (low in GOLD stage II, intermediate in GOLD stage III, and high in GOLD stage IV). Previous findings showed that this parameter can also be an important prognostic factor in patients with cardiovascular disease $[11,20$, 30].

Recovery kinetics parameters showed a significant association with exercise capacity in patients with COPD. Cardiopulmonary and gas exchange responses during the recovery phase of the $6 \mathrm{MWT}$ demonstrate differences in both the steepness of the curves as well as in $\mathrm{T}_{1 / 2} \mathrm{VO}_{2}$ across the GOLD stages. After adjustment for covariates, $\mathrm{T}_{1 / 2} \mathrm{VO}_{2}$ was independently associated with 6MWD.

The recovery of oxygen uptake after exercise in healthy humans is very fast and independent of the level of oxygen consumption attained at peak exercise [3]. As demonstrated in previously published work, we discovered that patients with advanced airflow limitation (higher GOLD stages) have altered oxygen uptake kinetics during rest-towork transition and a lower $\mathrm{VO}_{2 S S}$ [11]. In the current study, we analyzed the recovery of oxygen uptake kinetics 
after the 6MWT and found that both the steepness of the curve and $\mathrm{T}_{1 / 2} \quad \mathrm{VO}_{2}$ show significant differences between GOLD stages II, III, and IV. These findings suggest that the recovery of oxygen uptake kinetics after exercise in patients with COPD is altered and depends on the degree of airflow limitation and disease severity. Differences in recovery ability may play a predominant role in the way patients with COPD experience prolonged dyspnea or fatigue after exercise.

In healthy subjects, the time constant of oxygen uptake during cessation of submaximal exercise has traditionally been related to the compensation of an "oxygen debt" [31, 32]. This oxygen debt is incurred because of the delay in achievement of the steady state during the early minutes of exercise $[31,32]$. The term "oxygen debt" is still widely used to date; however, the underlying pathophysiological mechanisms that explain the delayed oxygen uptake kinetics after exercise in patients with cardiopulmonary diseases are more complex. Patients with COPD have a slow recovery of the ventilatory variables after exercise [33]. The slow recovery of ventilation most likely is a result of chronic airway obstruction and hyperinflation [34]. Chick et al. [34] analyzed the recovery of gas exchange after maximal cycle ergometry in 16 patients with COPD and 10 healthy control subjects. Besides the marked reduction in exercise capacity, they found that patients with COPD had prolonged relative hyperpnea, hypermetabolism, and tachycardia after exercise. Patients with COPD must keep ventilation high to eliminate venous $\mathrm{CO}_{2}$ that has formed during exercise. In addition, retention of $\mathrm{CO}_{2}$ tension in skeletal muscles and lower $\mathrm{pH}$ values after exercise may stimulate C-fiber discharges and maintain excess ventilation [35]. Because respiratory muscles have high-energy requirements, prolonged hyperpnea increases the cost of breathing after exercise and may, therefore, be responsible for the delay in oxygen uptake recovery.

Another mechanism that may cause the altered recovery of oxygen uptake kinetics after exercise is the presence of cardiovascular comorbidities. There is accumulating evidence that COPD is a systemic disease with significant cardiovascular manifestations, such as ischemic heart disease, stroke, arrhythmias, heart failure, and sudden cardiac death [36]. In patients with chronic heart failure, the time required for $\mathrm{VO}_{2}$ to recover after exercise is prolonged, and the slower recovery is associated with the severity of the disease $[3,17,18,37-39]$. The prolonged recovery time in patients with chronic heart failure may be a result of the impaired ability of the cardiocirculatory system to rapidly deliver the amount of oxygen needed to fully replenish myoglobin in the peripheral muscles $[3,40]$. In addition,

Oxygen Kinetics during Recovery of the 6-Minute Walk Test prolonged $\mathrm{CO}_{2}$ output kinetics during recovery from exercise may also play a significant role. Tanabe et al. [40] found that not only oxygen uptake during recovery from exercise was delayed, but also cardiac output fell much more slowly after maximal exercise. The delayed decrease in cardiac output during recovery in patients with chronic heart failure is predominantly responsible for $\mathrm{CO}_{2}$ elimination $[38,40]$.

Although cardiovascular disease is likely to be involved in the altered recovery of oxygen uptake kinetics after exercise in patients with COPD, well-controlled interventional studies are currently needed to establish a causal relationship. More knowledge regarding the altered recovery of oxygen uptake kinetics after exercise in patients with COPD may help to determine whether it has a significant bearing on the ability to perform exercise or participate in activities of daily living.

There is a growing interest in submaximal exercise parameters capable of objectively evaluating the functional capacity of patients with $\mathrm{COPD} . \mathrm{VO}_{2}$ on-kinetics were proven to be very successful in reflecting functional capacity in several studies $[11,41,42]$. In the current study, $\mathrm{VO}_{2}$ recovery kinetics $\left(\mathrm{T}_{1 / 2} \mathrm{VO}_{2}\right)$ were independently associated with exercise capacity as assessed by the 6MWD.

Patients' motivation during exercise testing may influence the exercise capacity estimated from parameters derived from oxygen kinetics. Postexercise parameters, such as $\mathrm{T}_{1 / 2} \mathrm{VO}_{2}$, are independently related to the on-kinetics phase and, therefore, may suffer from the same limitations.

Ventilatory and cardiac limitations may also play an important role with regard to the exercise capacity estimated from oxygen kinetics. Interestingly, $\mathrm{T}_{1 / 2} \mathrm{VO}_{2}$ significantly predicted patients' exercise capacity (6MWD) independently from these factors of limitation.

Finally, the effect of deconditioning (not assessed in the current study) frequently observed in patients with COPD and leading to muscle weakness/exercise intolerance may also have a major impact on oxygen kinetics in the context of the 6MWT [30].

\section{Limitations}

Firstly, it should be stressed that a causal relationship cannot be established from a cross-sectional study. Secondly, we did not control for the use of long-acting $\beta_{2^{-}}$ agonists on the day before measurements were performed, which may have had an effect on cardiac performance. In addition, the number of subjects was low given the variance in data. Further limiting factors of our study 
include the fact that $\mathrm{T}_{1 / 2} \mathrm{VO}_{2}$ could not be calculated in all patients. In some cases, the curve fit failed. Some of these patients were unable to perform the 6MWT with a constant walking speed or without interruptions. This fact may be the reason for the marked variability in $\mathrm{VO}_{2}$ in patients in whom curve fitting failed.

\section{Conclusions}

Both the steepness of the curves reflecting oxygen uptake recovery kinetics as well as $\mathrm{T}_{1 / 2} \mathrm{VO}_{2}$ differ across all GOLD stages. These findings suggest that the recovery of oxygen uptake kinetics after exercise in patients with COPD is altered and depends on advanced airflow limitation and disease severity. After adjustment for covariates, $\mathrm{T}_{1 / 2} \mathrm{VO}_{2}$ was independently associated with $6 \mathrm{MWD}$. Therefore, $\mathrm{T}_{1 / 2} \mathrm{VO}_{2}$ can be used to reflect exercise capacity in patients with COPD.

\section{Financial Disclosure and Conflicts of Interest}

The authors declare that they have no conflicts of interest.

\section{References}

1 Janicki JS, Gupta S, Ferris ST, et al: Long-term reproducibility of respiratory gas exchange measurements during exercise in patients with stable cardiac failure. Chest 1990;97:1217.

-2 American Thoracic Society/American College of Chest Physicians: ATS/ACCP Statement on Cardiopulmonary Exercise Testing. Am J Respir Crit Care Med 2003;167:211277.

-3 Cohen-Solal A, Laperche T, Morvan D, Geneves M, Caviezel B, Gourgon R: Prolonged kinetics of recovery of oxygen consumption after maximal graded exercise in patients with chronic heart failure. Circulation 1995;91: 2924-2932.

-4 Spruit MA, Polkey MI, Celli B, Edwards LD, Watkins ML, et al: Predicting outcomes from 6-min walk distance in chronic obstructive pulmonary disease. J Am Med Dir Assoc 2011;13:291-297.

5 Poole DC, Hirai DM, Copp SW, Musch TI: Muscle oxygen transport and utilization in heart failure: implications for exercise (in)tolerance. Am J Physiol Heart Circ Physiol 2012; 302:1050-1010.

6 Laveneziana P, Valli G, Onorati P, Paoletti P, Ferrazza AM, Palange P: Effect of heliox on heart rate kinetics and dynamic hyperinflation during high-intensity exercise in COPD. Eur J Appl Physiol 2011;111:225-234.

7 Puente-Maestu L, Sanz ML, Sanz P, Nunez A, Gonzalez F, Whipp BJ: Reproducibility of the parameters of the on-transient cardiopulmonary responses during moderate exercise in patients with chronic obstructive pulmonary disease. Eur J Appl Physiol 2001;85:434-441.

8 Hughson RL: Oxygen uptake kinetics: historical perspective and future directions. Appl Physiol Nutr Metab 2009;34:840-850.
\9 Chiappa GR, Borghi-Silva A, Ferreira LF, Carrascosa C, Oliveira CC, Maia J, Gimenes AC, Queiroga F Jr, Berton D, Ferreira EM, Nery LE, Neder JA: Kinetics of muscle deoxygenation are accelerated at the onset of heavyintensity exercise in patients with COPD: relationship to central cardiovascular dynamics. J Appl Physiol 2008;104:1341-1350.

10 Shimizu N, Koike A, Koyama Y, Kobayashi K, Marumo F, Hiroe M: Kinetics of pulmonary gas exchange during and while recovering from exercise in patients after anterior myocardial infarction. Jpn Circ J 1999;63:459466.

11 van Gestel AJR, Baty F, Rausch Osthoff AK, Brutsche M: Cardiopulmonary and gas-exchange responses during the six-minute walk test in patients with chronic obstructive pulmonary disease. Respiration 2014;88:4:307314.

12 Davies CT, Di Prampero PE, Cerretelli P: Kinetics of cardiac output and respiratory gas exchange during exercise and recovery. J Appl Physiol 1972;32:618-625.

13 Gaesser GA, Brooks GA: Metabolic bases of excess postexercise oxygen consumption: a review. Med Sci Sport Exerc 1984;16:29-43.

14 Di Prampero P, Davies CT, Cerretelli P, et al: An analysis of the oxygen debt contracted in submaximal exercise. J Appl Physiol 1970;29: 547-551.

15 Barstow TJ, Mole PA: Stimulation of pulmonary $\mathrm{O}_{2}$ uptake during exercise transients in humans. J Appl Physiol 1987;63:2253-2261.

16 Hagberg JM, Hickson RC, Ehsani AA, et al: Faster adjustment to and recovery from submaximal exercise in the trained state. J Appl Physiol Respir Environ Exercise Physiol 1980; 48:218-224.

17 Riley M, Stanford CF, Nicholls DP: Ventilatory and heart rate response after exercise in chronic cardiac failure. Clin Sci 1994;87:231238.
18 Sietsema KE, Ben-Dov I, Zhang YY, et al: Dynamics of oxygen uptake for submaximal exercise and recovery in patients with chronic heart failure. Chest 1994;105:1693-1700.

19 Tueller C, Kern L, Azzola A, Baty F, Condrau $\mathrm{S}$, Wiegand J, et al: Six-minute walk test enhanced by mobile telemetric cardiopulmonary monitoring. Respiration 2010;80:410418.

20 Kern L, Condreau S, Baty F, Wiegand J, van Gestel AJR, Tamm AAM, Brutsche M: Oxygen kinetics during 6-minute walk tests in patients with cardiovascular and pulmonary disease. BMC Pulm Med 2014;14:167.

21 ATS Committee on Proficiency Standards for Clinical Pulmonary Function Laboratories: ATS statement: guidelines for the six-minute walk test. Am J Respir Crit Care Med 2002; 166:111-117.

22 Guyatt GH, Pugsley SO, Sullivan MJ, Thompson PJ, Berman L, Jones NJ: Effect of encouragement on walking test performance. Thorax 1984;39:818-822.

23 R Development Core Team: R: A Language and Environment for Statistical Computing. Vienna, R Foundation for Statistical Computing, 2009.

24 Ritz C, Streibig JC: Bioassay analysis using R. J Stat Softw 2005;12:1-22.

25 Ritz C, Baty F, Streibig JC, Gerhard D: Doseresponse analysis using R. PLoS One 2015; 10:e0146021.

26 Gerhard D, Ritz C: Medrc: Mixed Effects Dose Response Curves. $\mathrm{R}$ package version $0.0-73$.

27 Pinheiro J, Bates D, DebRoy S, Sarkar D; R Core Team: Manual Linear and Nonlinear Mixed Effects Models 2013. R package version 3.1-113. 
28 Hothorn T, Bretz F, Westfall P: Simultaneous inference in general parametric models. Biom J 2008;50:346-363.

29 Baty F, Ritz C, van Gestel A, Brutsche M, Gerhard D: Modeling the oxygen uptake kinetics during exercise testing of patients with chronic obstructive pulmonary diseases using nonlinear mixed models. BMC Med Res Methodol 2016;16:66.

30 Papaioannou AI, Orfanos SE: "Every breath you take I'll be watching you": measuring exercise kinetics during 6-min walking test in COPD. Respiration 2014;88:449-450.

-31 Hill AV, Lupton H: Muscular exercise, lactic acid and the supply and utilization of oxygen. Q J Med 1923;16:135-171.

32 Margaria R, Edwards HT, Dill DB: The possible mechanisms of contracting and paying the oxygen debt and the role of lactic acid in muscular contraction. Am J Physiol 1933;106: 689-715.
33 Pineda H, Hans F, Axen K, Hans A: Accuracy of pulmonary function tests in predicting exercise tolerance in chronic obstructive pulmonary disease. Chest 1984;86:564-567.

34 Chick TW, Cagle TG, Vegas FA, Poliner JK, Murata GH: Recovery of gas exchange variables and heart rate after maximal exercise in COPD. Chest 1990;97:276-279.

35 Mancini DM, Ferraro N, Tuchler M, Chance B, Wilson JR: Detection of abnormal calf muscle metabolism in patients with heart failure using phosphorus-31 nuclear magnetic resonance. Am J Cardiol 1988;62:1234-1240.

6 Sidney S, Sorel M, Quesenberry CP, DeLuise C, Lanes S, Eisner MD: COPD and incident cardiovascular disease hospitalizations and mortality: Kaiser Permanente Medical Care Program. Chest 2005;128:2068-2075.

37 Hayashida W, Kumada T, Kohno F, et al: Post-exercise oxygen uptake kinetics in patients with left ventricular dysfunction. Int J Cardiol 1993;38:63-72.
38 Sietsema KE, Ben-Dov I, Zhang YY, et al: Dynamics of oxygen uptake for submaximal exercise and recovery in patients with chronic heart failure. Chest 1994;105:1693-1700.

39 De Groote P, Millaire A, Decoulx E, et al: Kinetics of oxygen consumption during and after exercise in patients with dilated cardiomyopathy. J Am Coll Cardiol 1996;28:168-175.

40 Tanabe M, Takahashi Y, Hosaka M, Ito E, Suzuki K: Prolonged recovery of cardiac output after maximal exercise in patients with chronic heart failure. J Am Coll Cardiol 2000;35: 1228-1236.

41 Puente-Maestu L, Sanz ML, Sanz P, Nunez A, Gonzalez F, Whipp BJ: Reproducibility of the parameters of the on-transient cardiopulmonary responses during moderate exercise in patients with chronic obstructive pulmonary disease. Eur J Appl Physiol 2001;85:434-441.

42 Hughson RL: Oxygen uptake kinetics: historical perspective and future directions. Appl Physiol Nutr Metab 2009;34:840-850. 